\title{
Wideband Multilayer Sierpinski Carpet Array Radar Absorber
}

DOI:

10.1049/el.2016.2702

\section{Document Version}

Accepted author manuscript

Link to publication record in Manchester Research Explorer

\section{Citation for published version (APA):}

Noor, A., \& Hu, Z. (2016). Wideband Multilayer Sierpinski Carpet Array Radar Absorber. Electronics Letters, 52(19), 1617-1618. https://doi.org/10.1049/el.2016.2702

\section{Published in:}

Electronics Letters

\section{Citing this paper}

Please note that where the full-text provided on Manchester Research Explorer is the Author Accepted Manuscript or Proof version this may differ from the final Published version. If citing, it is advised that you check and use the publisher's definitive version.

\section{General rights}

Copyright and moral rights for the publications made accessible in the Research Explorer are retained by the authors and/or other copyright owners and it is a condition of accessing publications that users recognise and abide by the legal requirements associated with these rights.

\section{Takedown policy}

If you believe that this document breaches copyright please refer to the University of Manchester's Takedown Procedures [http://man.ac.uk/04Y6Bo] or contact uml.scholarlycommunications@manchester.ac.uk providing relevant details, so we can investigate your claim.

\section{OPEN ACCESS}


Manuscript for Review

Wideband Multilayer Sierpinski Carpet Array Radar Absorber

\begin{tabular}{|r|l|}
\hline Journal: & Electronics Letters \\
\hline Manuscript ID & ELL-2016-2702.R1 \\
\hline Manuscript Type: & Letter \\
\hline Date Submitted by the Author: & $28-J u l-2016$ \\
\hline Complete List of Authors: & $\begin{array}{l}\text { Noor, Adnan; GHULAM ISHAQ KHAN INSTITUTE OF ENGINEERING } \\
\text { SCIENCES \& TECHNOLOGY, ELECTRONIC ENGINEERING } \\
\text { Hu, Zhirun; The University of Manchester, EEE; }\end{array}$ \\
\hline Meywords: & \begin{tabular}{l} 
METAMATERIALS, RADAR CROSS-SECTIONS, FRACTALS \\
\hline
\end{tabular} \\
\hline
\end{tabular}

SCHOLARONE $^{\text {M }}$

Manuscripts 


\section{Wideband Multilayer Sierpinski Carpet Array Radar Absorber}

\author{
A. Noor, Z. Hu
}

A novel multilayered wideband microwave absorber based on lossy Sierpinski carpet array has been proposed in this paper. The absorber consists of four layers of Sierpinski carpet arrays composed of lossy materials with varying conductivities. The absorber has $-10 \mathrm{~dB}$ absorption bandwidth of more than two octaves for normally incident wave and p-polarized obliquely incident wave, from 6 to $40 \mathrm{GHz}$. The thickness of the absorber $7.2 \mathrm{~mm}$. The structure does not contain any lumped elements and hence can be realized using 3D printing technology.

Introduction: The microwave absorbers have wide range of applications such as radar absorbers and anechoic chambers. From the energy conservation point of view when an electromagnetic wave is incident upon an object there are only two possible ways to reduce the scattering cross-section of the object; absorb the incoming radiation, or divert the incoming radiation around the object[1-4].

The basic principle of an electromagnetic wave absorber is matching the equivalent impedance of the absorber with that of the free space [1].

Standard Salisbury, Dallenbach and Jaumen Screens work on the principle of matching the structure impedance to that of the free space resulting in zero reflection for the incident wave. From the transmission line theory point of view a conducting surface observed from a distance less than quarter of wavelength would appear as an inductive load to the incident electromagnetic wave[1,5-6]. In order to match absorbers with less than quarter wavelength thickness to free space a resistivecapacitive element has to be inserted in shunt and/or in series. This can be achieved by using lossy resonant structures[1,7].

Ordinary resonant structures usually resonate at a certain fundamental frequency and its multiples[6,8]. A fractal resonator on the other hand has multiple length scales and hence resonances at multiple frequencies[9]. This feature makes it ideal for realizing wideband absorbers .

A periodically textured surface can also shows resonant behaviour [8] An ordinary waveguide array would resonate at a single frequency limiting the absorption bandwidth that can be achieved. As discussed earlier a fractal structure as a consequence of multiple length scales will resonate at multiple frequencies and will generally lead to a wider absorption bandwidth.

Usually resonances are introduced through inclusion of metallic patterns and lumped elements $[10,11]$. Such structures are known as circuit analogue absorbers. The structure presented in this work achieve the resonance through patterning of a homogeneous material and is thus possible to use $3 \mathrm{D}$ printing techniques.

\section{Structure:}

The structure is a 2D array with unit cell composed of four layers of 2nd order Sierpinski carpet. Different to conventional Sierpinski carpet, lossy material (e.g. a polymer / carbon black mixture) is proposed in this work. The size of the unit cell is $54 \mathrm{~mm}$ by $54 \mathrm{~mm}$ and all blank spaces are air filled. Thickness of each layer is $1.8 \mathrm{~mm}$ and the conductivity progressively increases from the top layer to the bottom layer. The conductivity for each layer are given in table 1 . The relative permittivity of each layer is 2.5 .

Table 1: The Conductivities of the layers used in the absorber.

\begin{tabular}{|l|l|}
\hline Layer & $\begin{array}{l}\text { Conductivity, } \\
\mathrm{Sm}^{-1}\end{array}$ \\
\hline 1 & 0.75 \\
\hline 2 & 1.25 \\
\hline 3 & 1.95 \\
\hline 4 & 3 \\
\hline
\end{tabular}

The purpose of this scheme for conductivity was to achieve good impedance matching, with low conductivity/high impedance layer in contact with free space and high conductivity/low impedance surface in contact with the ground plane. The structure is shown in Fig. 1.

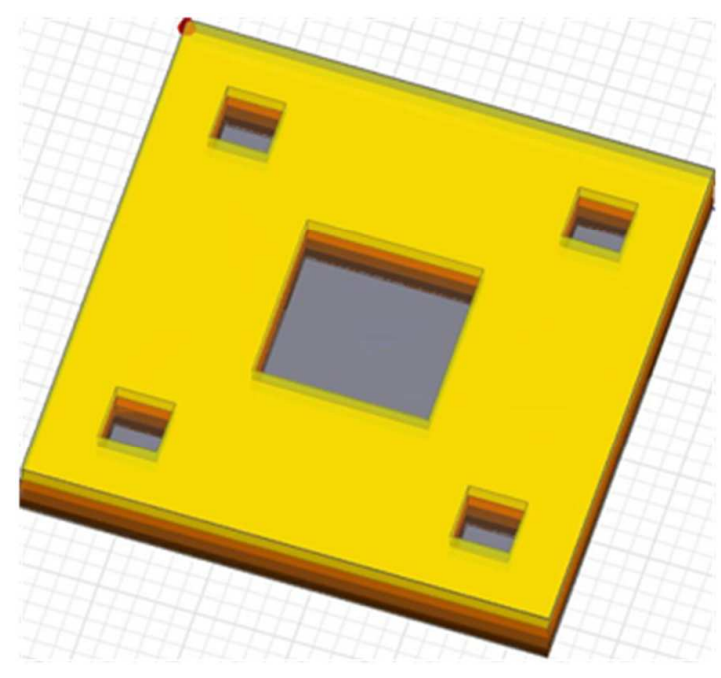

Fig. 1 The Unit Cell of the 4 layer Sierpinski absorber lines.

Results and discussions:

The structure was simulated using HFSS (High Frequency Simulation Structure).

Refection coefficients were evaluated over the frequency range from 4 to $40 \mathrm{GHz}$. The results showed a $-10 \mathrm{~dB}$ absorption bandwidth from 6 to $40 \mathrm{GHz}$. Radar absorbers differ widely in terms of thickness and bandwidth. For a given thickness there is an absolute limit on the absorption bandwidth of the absorber which depends on the number of resonances in the absorber structure [12]. The value of $\Delta \lambda=\lambda_{\max }-\lambda_{\min }$ depends on the thickness of the absorber. $\lambda_{\max }-\lambda_{\min }$ are the maximum and minimum wavelengths corresponding to the absorption bandwidth. The parameter $\Delta \lambda / \mathrm{d}$ where $\mathrm{d}$ is the thickness of the absorber, is thus a good performance parameter of an absorber. In order to evaluate the performance for a given thickness, the reflection as function of frequency is shown in Fig. 2

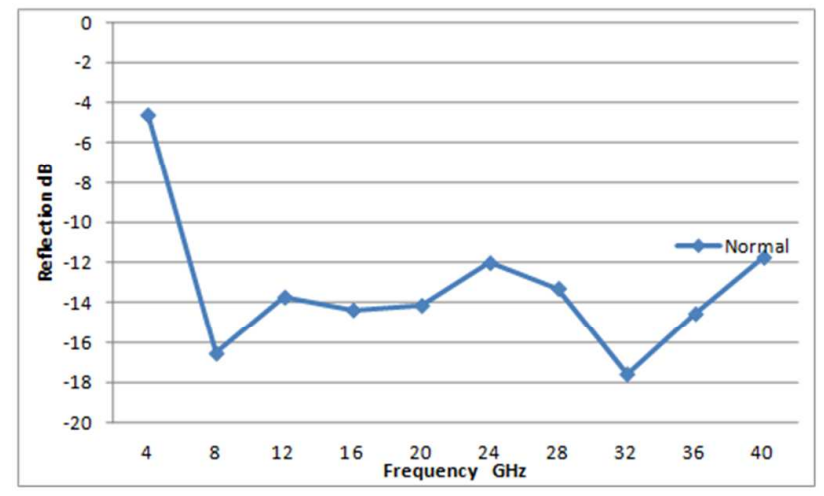

Fig. 2 Reflection coefficient $(d B)$ for the normal incidence

The bandwidth ranges from $6 \mathrm{GHz}$ to $40 \mathrm{GHz}$. This corresponds to $\lambda_{\max }$ of $50 \mathrm{~mm}$ and $\lambda_{\min }$ of $7.5 \mathrm{~mm} . \Delta \lambda$ is then 42.5 or in $\Delta \lambda / \mathrm{d}$ of 5.9 $(\mathrm{d}=7.2 \mathrm{~mm})$. This value of $\Delta \lambda / \mathrm{d}$ greater than what is possible with non-resonant absorbers. The approximate equation for the maximum value of $\Delta \lambda / \mathrm{d}$ for non resonant and non magnetic absorber is given by $\frac{\Delta \lambda_{\max }}{d}=\frac{32}{\pi \rho_{o}}$ where $\rho_{o}$ is the maximum allowed magnitude of the reflection coefficient in the absorption band [12]. For $-10 \mathrm{~dB}$ absorption the maximum value of $\Delta \lambda / \mathrm{d}$ is around 3.2. One of the reason for enhanced performance for the absorber reported in this work is coupling of the incident wave to the surface wave modes of the structure. 
Coupling to the surface wave can be inferred from the disparity between the results for $\mathrm{S}$ and $\mathrm{P}$ polarized waves for oblique incidence. The aforementioned point is discussed in detail at the end of this section. The absorber presented in this work achieves the performance of ultra wideband circuit analogue absorbers without the need of complex fabrication process.

The simulation was then repeated for oblique incidence of $30^{\circ}$ and $60^{\circ}$ for both S polarization (TE) and P polarization (TM). The results are given in Fig. 3 .

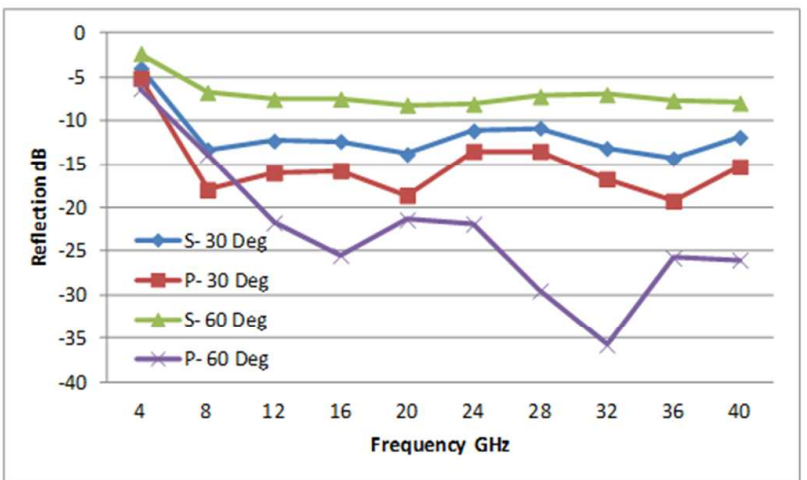

Fig. 3 Reflection coefficient ( $d B)$ for oblique incidence. Results are shown for $S$ polarized (TE) and P polarized (TM) for $30^{\circ}$ and $60^{\circ}$ incidence.

It can observed that absorption is still very good for $\mathrm{P}$ polarized waves (TM) and the $-10 \mathrm{~dB}$ absorption bandwidth is from 6 to $40 \mathrm{GHz}$. As can be observed from the results, TM wave absorption is much stronger compared to TE absorption. This disparity between absorption of $\mathrm{P}$ polarized waves (TM) and S polarized waves (TE) indicates that the absorption is enhanced due to critical coupling of the incident wave to the surface wave modes of the Sierpinski carpet $[8,13]$. TM or P polarized waves were more effectively couple to the surface wave hence the absorption is much stronger for that of TE or S polarized waves [8].

\section{Conclusion:}

The Sierpinski carpet composed of lossy dielectric act as a wideband microwave absorber with a $-10 \mathrm{~dB}$ absorption bandwidth of almost 3 octaves. Even for oblique incidence the absorption bandwidth is from 6$40 \mathrm{GHz}$ for TM waves.

The structure can be 3D printed as it does not require inclusion of lumped elements. Such structure will be very useful in realizing low cost easily fabricated radar absorbers. .

A. Noor (Ghulam Ishaq Khan Institute of Engineering Sciences and Technology,Pakistan ) E-mail: adnannoor@giki.edu.pk

Z. Hu (University of Manchester, U.K)

\section{References}

1. Emerson, W.H.: 'Electromagnetic wave absorbers and anechoic chambers through the years', IEEE Transactions on Antennas and Propagation., 1973, 21, pp. 484-493,

2. Engheta, N., Alù, A.: 'Achieving transparency with plasmonic and metamaterial coatings', Phys. Rev. E, 2005, 016623

3. Pendry, J.B, Schurig,D., Smith, D.R.: 'Controlling electromagnetic fields', Science., 2006, 312, pp. 1780-1782

4. Ward, A.J, Pendry, J.B.: 'Refraction and geometry in Maxwell's equations', Journal Of Modern Optics., 1996, 43, pp. 773-793

5. Pozar, D.M,.: 'Microwave Engineering', (John Wiley \& Sons, 1999, second edition)

6. Balanis, C.A.: 'Advanced Engineering Electromagnetics', (John Wiley \& Sons, 1989)
7. Chambers, B.: 'Frequency tuning characteristics of capacitively loaded Salisbury screen radar absorber', Electronics Letters, 1994, 30, pp. $1626-1628$

8. Maier, S.A,.: 'Plasmonics', (Springer, 2007)

9. Werner, D.H., Ganguly, S.: 'An overview of fractal antenna engineering research', IEEE Antennas and Propagation Magazine, 2003, 45(1), pp. 38-57

10. Zheng, B., Shen, Z.: 'Wideband radar absorbing material combining high-impedance transmission line and circuit analogue screen', Electronics Letters, 2007, 44, pp. 318-319

11. Tang, W., Shen, Z.: 'Simple design of thin and wideband circuit analogue absorber', Electronics Letters, 2007, 43, pp. 689-691

12. Rozanov, K.N., Starostenko, S.N.: 'Numerical study of bandwidth of radar absorbers', Eur. Phys. J. AP, 1999, 8, pp. 147-151

13. Piper, J.R.., Fan, S.: 'Total Absorption in a Graphene Monolayer in the Optical Regime by Critical Coupling with a Photonic Crystal Guided Resonance', ACS Photonics, 2014, 1(4), pp. 347-353 